\title{
Continuous SiC skeleton reinforced highly oriented graphite flake composites with high strength and specific thermal conductivity
}

\author{
Xiaoyu ZHANG ${ }^{a, \dagger}$, Wenqi XIE ${ }^{a, \dagger}$, Lan $\mathrm{SUN}^{a}$, Zhilei WEI ${ }^{a}$, Zhejian $\mathrm{ZHANG}^{a}$, \\ Yuanyuan $\mathrm{ZHU}^{a}$, Jiabin $\mathrm{HU}^{a}$, Shenghe $\mathrm{WANG}^{b}$, Zhongqi $\mathrm{SHI}^{a,{ }^{*}}$ \\ ${ }^{a}$ State Key Laboratory for Mechanical Behavior of Materials, Xi'an Jiaotong University, Xi'an 710049, China \\ ${ }^{b}$ State Grid Anhui Electric Power Co., Ltd., Hefei 230061, China
}

Received: July 6, 2021; Revised: September 28, 2021; Accepted: October 1, 2021

(c) The Author(s) 2021.

\begin{abstract}
Highly oriented graphite-based composites have attracted great attention because of their high thermal conductivity (TC), but the low mechanical properties caused by the inhomogeneous distribution and discontinuity of reinforcements restrict the wide applications. Herein, continuous $\mathrm{SiC}$ ceramic skeleton reinforced highly oriented graphite flake (SiC/GF) composites were successfully prepared by combining vacuum filtration and spark plasma sintering. The effect of $\mathrm{SiC}$ concentration on the microstructure, flexural strength, and thermophysical properties of the composites was investigated. The GF grains in the composites exhibited high orientation with a Lotgering factor of $>88 \%$ when the $\mathrm{SiC}$ concentration was $\leqslant 30 \mathrm{wt} \%$, and the $\mathrm{SiC}$ skeleton became continuous with the $\mathrm{SiC}$ concentration reaching $20 \mathrm{wt} \%$. The formation of continuous $\mathrm{SiC}$ skeleton improved the flexural strength of the composites effectively while keeping the TC in a high level. Especially, the composites with $30 \mathrm{wt} \% \mathrm{SiC}$ exhibited the flexural strength up to $105 \mathrm{MPa}$, and the specific TC reaching $0.118 \mathrm{~W} \cdot \mathrm{m}^{2} \cdot \mathrm{K}^{-1} \cdot \mathrm{kg}^{-1}$. The composites with excellent flexural strength and thermophysical properties showed significant promise for thermal management applications.
\end{abstract}

Keywords: ceramics; composite materials; high orientation; flexural strength; heat conduction

\section{Introduction}

Nowadays, the intelligent electronic devices have been developed towards high power density and miniaturization direction, which arouses urgent requirement for the thermal management materials (TMMs) with excellent performance [1-4]. The advanced TMMs should have the characteristics of low density, high strength, and high thermal conductivity (TC) perpendicular to the

$\dagger$ Xiaoyu Zhang and Wenqi Xie contributed equally to this work.

* Corresponding author.

E-mail: zhongqishi@mail.xjtu.edu.cn
electronic/TMM interface for effective heat dissipation. Besides, similar coefficient of thermal expansion (CTE) with those of semiconductor chips $\left(4 \times 10^{-6}-7 \times 10^{-6} \mathrm{~K}^{-1}\right)$ along the interface direction is necessary to minimize the thermal strain during operation [5-8].

Graphite materials as promising TMMs have attracted great attention because of the high TC in basal plane, light weight, and low cost. To take full advantage of outstanding in-plane TC of graphite, it is an efficient way to make graphite flake (GF) alignment to obtain highly oriented graphite blocks. By this means, the graphite blocks with high crystal orientation display ultrahigh TC $\left(550-700 \mathrm{~W} \cdot \mathrm{m}^{-1} \cdot \mathrm{K}^{-1}\right)[9,10]$. Nevertheless, 
inferior mechanical properties and high CTE in outplane direction of the highly oriented graphite blocks lead to the failure under harsh service environments [11]. In order to overcome the obstacles, some studies attempted to promote the mechanical properties of the graphite-based composites by using metal and ceramic powers (such as $\mathrm{Cu}, \mathrm{AlN}$, and $\mathrm{SiC}$ ) as reinforcements [12-14]. However, the huge differences between metal/ceramic powders and GF particles in size, shape, and dimension lead to the inhomogeneous distribution of metal/ceramic reinforcements in GF matrix [15], which makes the flexural strength improvement rather limited. For instance, Ren et al. [16] reported that the flexural strength of the $\mathrm{Cu} / \mathrm{GF}$ composites was only $\sim 50 \mathrm{MPa}$ when the volume fraction of $\mathrm{Cu}$ was $50 \%$. On account of this, the rational design and fabrication of the inorganic substance reinforced highly oriented GF composites are actively pursued.

Generally, highly oriented GF-based materials are consolidated by spark plasma sintering (SPS) or hot-pressing because the thin GF particles with platelet geometry (large length to thickness ratio) can be deflected and aligned by the sintering pressure [17]. Based on the finite element simulation and experimental results, the mechanical and thermophysical properties of highly oriented graphite-based materials can be optimized by constructing three-dimensional (3D) topological and continuous skeleton as reinforcement in the composites [18-21]. Therefore, various 3D continuous networks including metals (such as $\mathrm{Cu}$ and Al) $[14,22]$ and ceramics (AlN, WC) $[23,24]$ have been used to promote the mechanical properties of highly oriented graphite-based composites. Among them, the $\mathrm{Cu}$ skeleton with high density results in low specific TC, i.e., TC divided by density, which is unsatisfied with the light weight requirement for advanced TMMs. For the $\mathrm{Al}$ reinforced $\mathrm{GF}$ composites, it is widely accepted that the formation of $\mathrm{Al}_{4} \mathrm{C}_{3}$ at the $\mathrm{GF} / \mathrm{Al}$ interface during high temperature sintering would degrade the TC and chemical stability of the composites [4]. For the ceramic reinforcements, the $\mathrm{SiC}$ skeleton stands out because it possesses low density $\left(3.21 \mathrm{~g} \cdot \mathrm{cm}^{-3}\right)$, high flexural strength $(550 \mathrm{MPa})$, and high TC $\left(490 \mathrm{~W} \cdot \mathrm{m}^{-1} \cdot \mathrm{K}^{-1}\right.$ for single crystalline, $270 \mathrm{~W} \cdot \mathrm{m}^{-1} \cdot \mathrm{K}^{-1}$ for polycrystalline) [25]. Moreover, its CTE of about $4 \times 10^{-6} \mathrm{~K}^{-1}[26,27]$, much lower than that of GF in through-plane direction $\left(28 \times 10^{-6} \mathrm{~K}^{-1}\right)$, can introduce tensile stress in GF along this direction and hence reduce the CTE of the composites [17]. This improves the reliability of SiC reinforced GF composites as TMMs for electronic devices after repetitive thermal cycles. Therefore, preparing $3 \mathrm{D}$ continuous $\mathrm{SiC}$ skeleton reinforced highly oriented GF composites is an appealing approach to synergistically optimize the mechanical and thermophysical properties of highly oriented graphite-based composites.

Herein, we demonstrated a method combining vacuum filtration and SPS to realize the 3D continuous $\mathrm{SiC}$ skeleton reinforced highly oriented GF-matrix ( $\mathrm{SiC} / \mathrm{GF})$ composites. Vacuum filtration is a universal technique to fabricate well aligned GFs on account of the flowdirected assembly of two-dimensional (2D) carbon/ graphite particles (i.e., graphene or GF) with good orientation [28,29]. SPS is an efficient process not only for preparing high performance ceramics and composites in a short sintering time at relatively low temperature [30,31], but also for promoting the orientation of anisotropic particles by sintering pressure [32]. Thereby, the $3 \mathrm{D}$ continuous $\mathrm{SiC}$ skeleton can be successfully introduced in the highly oriented GF matrix, and the anisotropic SiC/GF composites with high strength and specific TC in plane direction were achieved. The effect of $\mathrm{SiC}$ weight fraction on the microstructure, flexural strength, and thermophysical properties of the composites were systematically investigated.

\section{Experimental}

\section{1 Sample preparation}

The raw materials were GF particles (purity $99.8 \%$, Alfa Aesar, USA) and $\alpha$-SiC powders (purity $99.9 \%$, Shanghai St-nano Science and Technology Co., Ltd., China). Figure 1 shows the micrographs of GFs and $\alpha$-SiC powders. The averaged lateral size and thickness of GFs are about 15 and $1 \mu \mathrm{m}$, respectively, and $\alpha$-SiC powders exhibit irregular morphology with an average size of $0.5 \mu \mathrm{m} .5 \mathrm{wt} \%$ of $\mathrm{Al}_{2} \mathrm{O}_{3}$ (purity $99 \%$, Sinopharm Chemical Reagent Co., Ltd., China) and $\mathrm{Y}_{2} \mathrm{O}_{3}$ (purity 99\%, Sinopharm Chemical Reagent Co., Ltd., China)
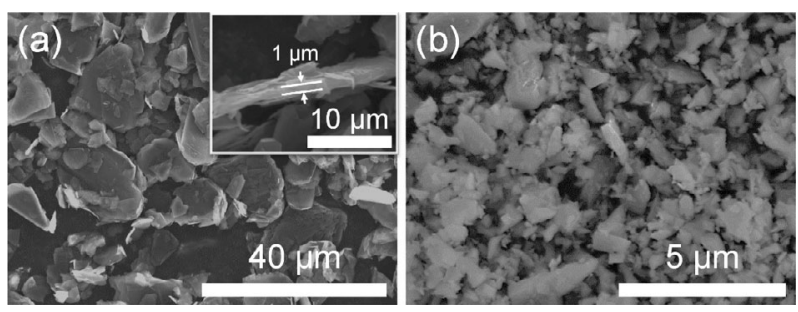

Fig. 1 Morphologies of (a) GF and (b) SiC powders. 
powders with a weight ratio of 2:1 were added as sintering aids. To explore the influence of $\mathrm{SiC}$ concentration on the microstructure and properties of the composites, the amounts of $\mathrm{SiC}$ powders were set as $15 \mathrm{wt} \%$, $20 \mathrm{wt} \%, 25 \mathrm{wt} \%, 30 \mathrm{wt} \%$, and $50 \mathrm{wt} \%$, and $\mathrm{SiC} 15 / \mathrm{GF}$, $\mathrm{SiC} 20 / \mathrm{GF}, \mathrm{SiC} 25 / \mathrm{GF}, \mathrm{SiC} 30 / \mathrm{GF}$, and $\mathrm{SiC} 50 / \mathrm{GF}$ were named for the resultant composites in the following discussion, respectively.

The $\mathrm{SiC} / \mathrm{GF}$ composites were fabricated by vacuum filtration followed by SPS, and the schematic illustration of the fabrication process is shown in Fig. 2. All the powders were weighted and ball-milled for $5 \mathrm{~h}$ in a polyethylene bottle using ethanol as the mixing media. Then the wet bodies were prepared by vacuum filtration of the as-received slurries. The micrographs of powders after ball milling and vacuum filtration are exhibited in Fig. S1 in the Electronic Supplementary Material (ESM). The size of GF remains unchanged (Fig. S1(a) in the ESM) and the GFs are aligned roughly at atmospheric pressure during vacuum filtration (Fig. S1(b) in the ESM). After removing the ethanol of the wet body at $80{ }^{\circ} \mathrm{C}$ for $24 \mathrm{~h}$, the obtained green body was put into a graphite die and sintered at $1800{ }^{\circ} \mathrm{C}$ for 5 min, applying $50 \mathrm{MPa}$ uniaxial pressure and under the vacuum $(5 \mathrm{~Pa})$ using a SPS furnace (Ed-PASIII, Elenix Ltd., Japan). The sintered samples were machined by wire-electrode cutting, then ground by $2000 \#$ sandpapers, and polished in different orientations to achieve the required dimensions for the following flexural strength, electrical conductivity, and thermophysical properties tests.

\section{2 Characterization}

The bulk density $(\rho)$ and relative density $\left(\rho_{\mathrm{RD}}\right)$ were

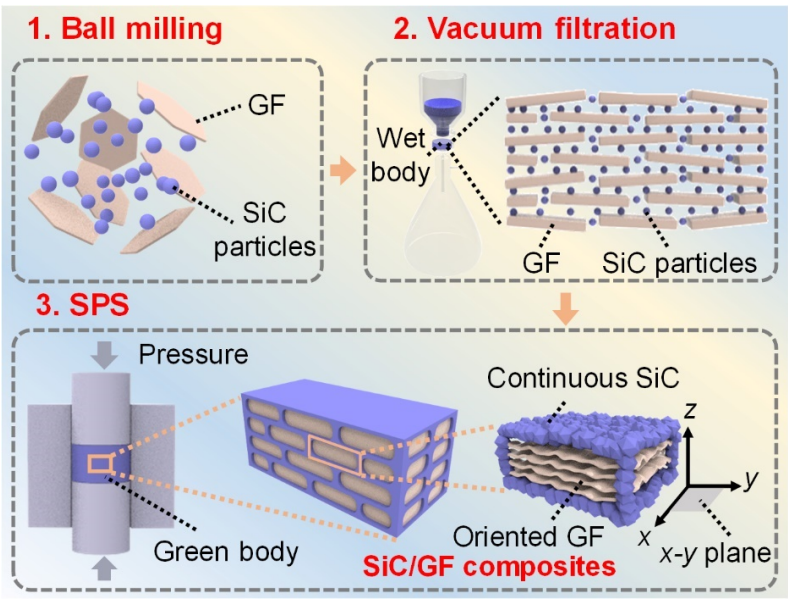

Fig. 2 Schematic illustration of the fabrication process of $\mathrm{SiC} / \mathrm{GF}$ composites. measured by Archimedes method (the detailed procedure shown in Section S2 in the ESM), using deionized water as immersion medium. Phase identification was performed by X-ray diffraction (XRD; X-Pert Pro, the Netherlands) with $\mathrm{Cu} \mathrm{Ka}$ radiation. The Lotgering factor $f$ of $(00 l)$ of graphite phase, obtained from XRD patterns, was calculated by Eq. (1) [33]:

$$
f_{(00 l)}=\left(P_{(00 l)}-P_{0}\right) /\left(1-P_{0}\right)
$$

where

$$
\begin{gathered}
P_{(00 l)}=\left(\sum I_{(00 l)}\right) /\left(\sum I_{(h k l)}\right) \\
P_{0}=\left(\sum I_{0(00 l)}\right) /\left(\sum I_{0(h k l)}\right)
\end{gathered}
$$

In Eq. (2), $\sum I_{(00 l)}$ and $\sum I_{(h k l)}$ are the integrated intensities of the $(00 l)$ peaks of graphite and all the $(h k l)$ peaks of graphite in the oriented sample pattern, respectively. In Eq. (3), $\sum I_{0(00 l)}$ and $\sum I_{0(h k l)}$ are the summation of the $(00 l)$ peaks of graphite and all the $(h k l)$ reflections of graphite in random crystallographic orientation sample, respectively. The $f$ value is between 0 and 1 , and higher value demonstrates the higher degree of orientation. All the micrographs of the samples were observed through a tungsten filament scanning electron microscope (SEM; SU3500, Hitachi, Japan). The polished and fractured surfaces of the $\mathrm{SiC} / \mathrm{GF}$ composites were examined by backscattered electron image (BEI) mode and secondary electron image (SEI) mode, respectively. The interfacial configuration was observed using the high-resolution transmission electron microscope (HRTEM; JEM-2100F, Japan). Raman spectra were characterized by a spectrometer (Nanofinder FLEXG, Tokyo Instruments Inc., Japan) with a $633 \mathrm{~nm}$ laser as the excitation light source.

The flexural strength, electrical conductivity, and thermophysical properties were measured in both perpendicular $(x-y$ plane) and parallel ( $z$ axis) to the sintering pressure directions. The sizes of sintered samples and schematics of specimens cut for the different tests and orientations are shown in Fig. S2 in the ESM. The flexural strength $\left(\sigma_{\mathrm{f}}\right)$ of the sample with a dimension of $3 \mathrm{~mm} \times 4 \mathrm{~mm} \times 16 \mathrm{~mm}$ was tested by three-point bending method with a crossed speed of $0.5 \mathrm{~mm} \cdot \mathrm{min}^{-1}$ at room temperature. The thermal diffusivity $(\alpha)$ was measured by the light flash method (Netzsch LFA447 NanoFlash, Germany) at room temperature. For the thermal diffusivity measurements in $z$ axis and $x-y$ plane directions, the dimensions of specimens were $\varnothing 12.7 \mathrm{~mm} \times 3 \mathrm{~mm}$ and $10 \mathrm{~mm} \times 10 \mathrm{~mm} \times 3 \mathrm{~mm}$, respectively. Two alloy holders were used for the TC 
tests (Fig. S3 in the ESM). The specific heat capacity $\left(C_{p}\right)$ of the $\mathrm{SiC} / \mathrm{GF}$ composites was obtained by the linear rule of mixtures. The TC value $(\lambda)$ was calculated by multiplying $\alpha, C_{p}$, and $\rho$. Then, the $\lambda$ divided by $\rho$ equals the specific TC. Surface temperature distribution of the composites on a homoiothermal $\mathrm{Cu}$ block was tested by an infrared thermal imager (Fotric 280, USA). The thermal expansion behavior was studied via a dilatometer (Netzsch DIL 402C, Germany) in the temperature range of $20-350{ }^{\circ} \mathrm{C}$ with a constant heating rate of $5{ }^{\circ} \mathrm{C} \cdot \mathrm{min}^{-1}$. The expansion was conducted on the sample with a dimension of $5 \mathrm{~mm} \times 5 \mathrm{~mm} \times$ $10 \mathrm{~mm}$. The electricity conductivity (EC) with the size of $3 \mathrm{~mm} \times 4 \mathrm{~mm} \times 10 \mathrm{~mm}$ was measured by the four probe method (Linseis LSR-3, Germany) in a helium atmosphere.

\section{Results and discussion}

\section{1 Phase composition and microstructure}

Figure 3(a) shows the XRD patterns of the $\mathrm{SiC} 30 / \mathrm{GF}$ composite in $x-y$ plane and $z$ axis directions. The diffraction peaks of $\alpha-\mathrm{SiC}$ and graphite phases in the composite can be detected. Besides, $\mathrm{AlYO}_{3}$ phase is also found, which was probably derived from the eutectic reaction of $\mathrm{Al}_{2} \mathrm{O}_{3}$ and $\mathrm{Y}_{2} \mathrm{O}_{3}$ to facilitate the sintering process $[34,35]$. Significant differences are shown in two principle directions of the composite. The intensity of (002) diffraction peak of graphite in $x-y$ plane at $2 \theta=26.5^{\circ}$ is about 200 times higher than that in $z$ axis direction, indicating the strong orientation of $\mathrm{GF}$ in the composites. Lotgering factor $f$ values calculated from the XRD patterns of the SiC/GF composites with different $\mathrm{SiC}$ concentrations (Fig. S4 in the ESM) are higher than $88 \%$ when the $\mathrm{SiC}$ concentration is $\leqslant 30 \mathrm{wt} \%$. This indicates that most of the GFs are aligned along the direction perpendicular to the sintering pressure. When the $\mathrm{SiC}$ concentration reaches $50 \mathrm{wt} \%$, the $f$ value declines sharply to $52 \%$, indicating that the introduction of $\mathrm{SiC}$ disturbs the arrangement of GFs. The intensity ratios of the D and G peaks $\left(I_{\mathrm{D}} / I_{\mathrm{G}}\right)$ of graphite characterized by the Raman spectra (Fig. S5 in the ESM) are used to investigate the crystalline quality of GF after sintering. The smaller $I_{\mathrm{D}} / I_{\mathrm{G}}$ value expresses the higher crystalline quality of GF [36]. With the increase of $\mathrm{SiC}$ concentration, the $I_{\mathrm{D}} / I_{\mathrm{G}}$ value of the graphite increases from 0.32 to 0.66 (Fig. 3(b)), which can be ascribed to the fracture and deformation of the GFs during the ball milling and SPS processes. The disorder of GF crystals will lead to the reduction of the phonon mean free path and be inferior to the phonon vibration as well as the heat conductivity [10].

The BEIs of polished surfaces parallel to $z$ axis direction of the composites with different $\mathrm{SiC}$ concentrations are shown in Figs. 4(a)-4(e). The bright areas are identified as $\mathrm{SiC}$ and dark regions refer to GF. A small number of pores can be observed in the $\mathrm{SiC} / \mathrm{GF}$ composites when the $\mathrm{SiC}$ concentration is lower than $50 \mathrm{wt} \%$. As the concentration of $\mathrm{SiC}$ increases, the number of pores gradually reduces and the pores finally disappear in the SiC50/GF composite, which demonstrates that the increase of $\mathrm{SiC}$ concentration is beneficial to the densification of the composites. The patterns of $\mathrm{SiC}$ phase are approximately parallel to each other, indicating the composites possess good orientation. It also can be seen that the $\mathrm{SiC}$ particles disperse discretely in GF matrix when the fraction of $\mathrm{SiC}$ is $15 \mathrm{wt} \%$. With the $\mathrm{SiC}$ concentration increasing to $20 \mathrm{wt} \%$, the $\mathrm{SiC}$ reinforcement begins to be continuous in the composite (the inset in Fig. 4(b)) and bridges to form a network architecture. After decarburizing of the $\mathrm{SiC} 20 / \mathrm{GF}$ composite at $700{ }^{\circ} \mathrm{C}$ for $5 \mathrm{~h}$, the oriented porous $\mathrm{SiC}$ skeleton can be obtained (Fig. 4(f)), which
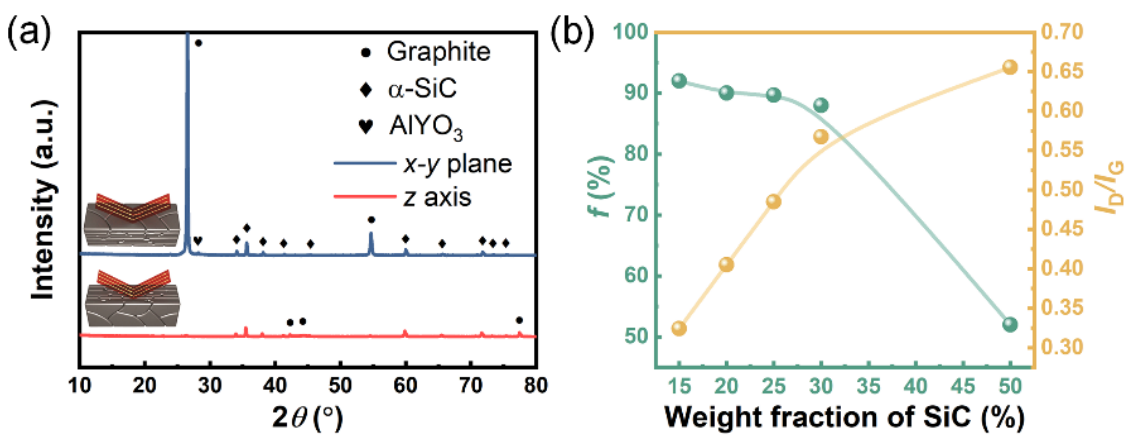

Fig. 3 (a) XRD patterns of SiC30/GF composite in two principle directions. (b) Lotgering factor $f$ values of (002) plane and the intensity ratios of $\mathrm{D}$ to $\mathrm{G}$ peaks $\left(I_{\mathrm{D}} / I_{\mathrm{G}}\right)$ of graphite in $\mathrm{SiC} / \mathrm{GF}$ composites. 

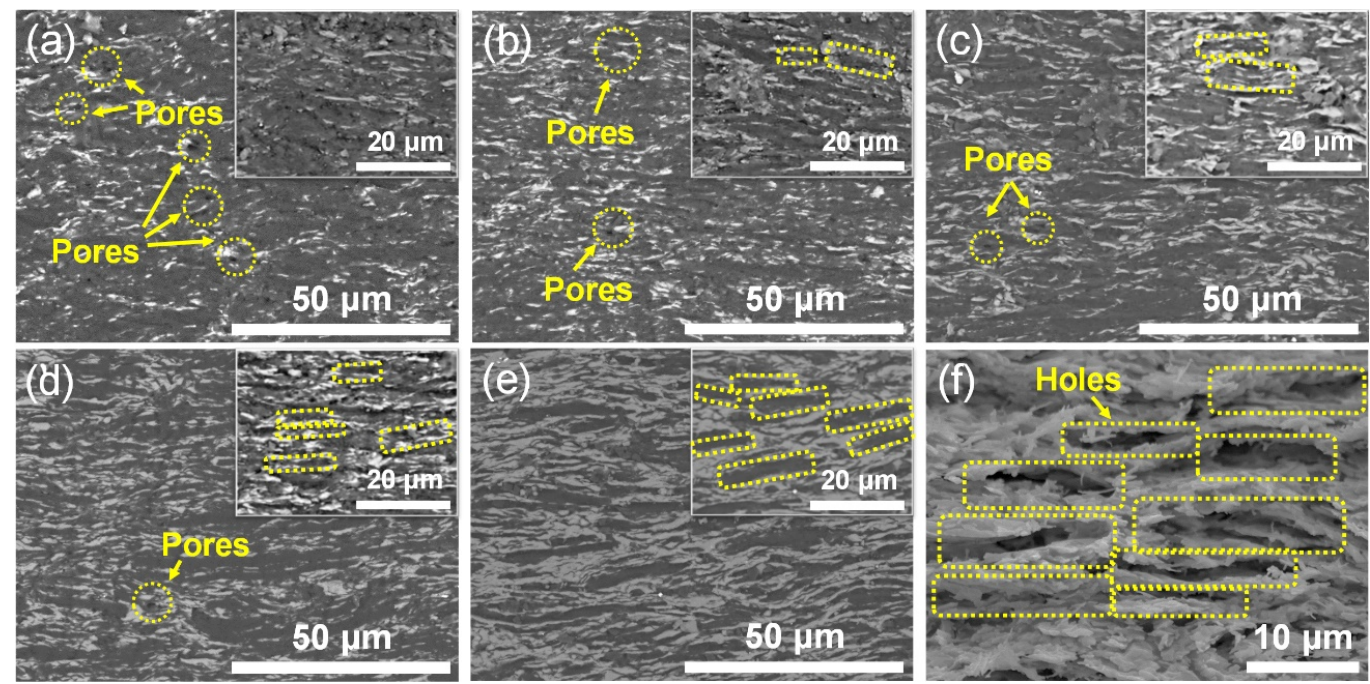

Fig. 4 BEIs of polished surfaces (parallel to $z$ axis direction) of (a) SiC15/GF, (b) SiC20/GF, (c) SiC25/GF, (d) SiC30/GF, and (e) $\mathrm{SiC} 50 / \mathrm{GF}$ composites, where the insets in (a-e) are the magnified images corresponding to the polished surfaces. (f) Microstructure of the decarbonized SiC20/GF composite.

further verifies the $3 \mathrm{D}$ continuity of the skeleton. The holes in the SiC skeleton shown in Fig. 4(f) (noted by the yellow dotted lines) have a length of $\sim 15 \mu \mathrm{m}$ and the thickness of 3-5 $\mu \mathrm{m}$, illustrating that a structural unit of the "cell-like" composite contains several stacked GFs. With further increase of the $\mathrm{SiC}$ concentration to $50 \mathrm{wt} \%$, almost all the GFs are surrounded by the integrated $\mathrm{SiC}$ skeleton and isolated as islands in the composite (Fig. 4(e)).

In order to clarify the connectivity of $\mathrm{SiC}$ in the $\mathrm{SiC} / \mathrm{GF}$ composites, the EC tests were conducted and the results are shown in Fig. 5. With the increase of $\mathrm{SiC}$ concentration, the $z$ axial EC decreases one order of magnitude from $0.06 \mathrm{MS} \cdot \mathrm{m}^{-1}$ for $\mathrm{SiC} 15 / \mathrm{GF}$ to $0.005 \mathrm{MS} \cdot \mathrm{m}^{-1}$ for $\mathrm{SiC} 20 / \mathrm{GF}$ and then remains basically unchanged, indicating that the $\mathrm{SiC}$ reinforcement in the interlayer of GFs begins to be continuous with the $\mathrm{SiC}$ concentration achieving $20 \mathrm{wt} \%$. The $x-y$ plane EC increases first from 0.07 to $0.11 \mathrm{MS} \cdot \mathrm{m}^{-1}$ as the $\mathrm{SiC}$

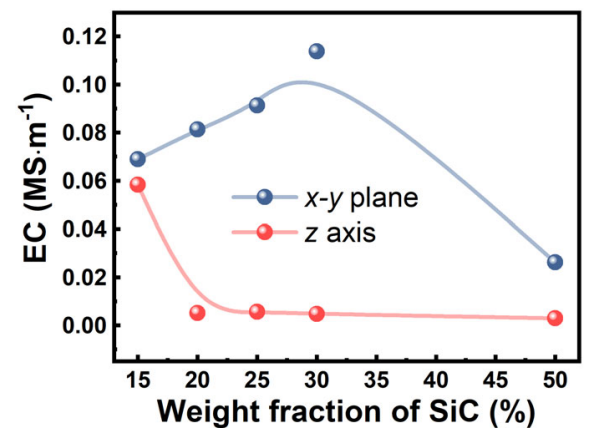

Fig. $5 \mathrm{EC}$ of $\mathrm{SiC} / \mathrm{GF}$ composites in $x-y$ plane and $z$ axis directions. concentration increases from 15 to $30 \mathrm{wt} \%$ and then drops to $0.03 \mathrm{MS} \cdot \mathrm{m}^{-1}$ when the $\mathrm{SiC}$ concentration reaches $50 \mathrm{wt} \%$. The increase of $\mathrm{EC}$ with the $\mathrm{SiC}$ concentration is mainly ascribed to the increase of relative density, which makes the GFs connected tightly. However, when the $\mathrm{SiC}$ concentration achieves $50 \mathrm{wt} \%$, the significant reduction of EC demonstrates that the integral 3D $\mathrm{SiC}$ skeleton is formed, which separates the GF grains thoroughly.

\section{2 Density and flexural strength}

Figure 6(a) shows the densities and relative densities of the composites with different $\mathrm{SiC}$ concentrations. It can be seen that the density increases gradually from $2.26 \mathrm{~g} \cdot \mathrm{cm}^{-3}$ for $\mathrm{SiC} 15 / \mathrm{GF}$ to $2.61 \mathrm{~g} \cdot \mathrm{cm}^{-3}$ for $\mathrm{SiC} 50 / \mathrm{GF}$, and the relative density increases correspondingly from $93.3 \%$ to $95.7 \%$, which indicates that the $\mathrm{SiC}$ is beneficial to the densification of the GF-based composites. This is also consistent with the microstructure of the $\mathrm{SiC} / \mathrm{GF}$ composites (Figs. 4(a)-4(e)). It is supposed that not only the densification of $\mathrm{SiC}$ reinforcements but also the growth of $\mathrm{SiC}$ grains contributes to the fill of the gaps between the GF grains during SPS, leading to the densification of the $\mathrm{SiC} / \mathrm{GF}$ composites.

The flexural strengths of the composites in two principle directions are exhibited in Fig. 6(b). It can be seen that the flexural strength in two principle directions almost grows linearly as the $\mathrm{SiC}$ concentration increases. The flexural strength rises from $67 \mathrm{MPa}$ for $\mathrm{SiC} 15 / \mathrm{GF}$ to $100 \mathrm{MPa}$ for $\mathrm{SiC} 30 / \mathrm{GF}$ when the loading direction 

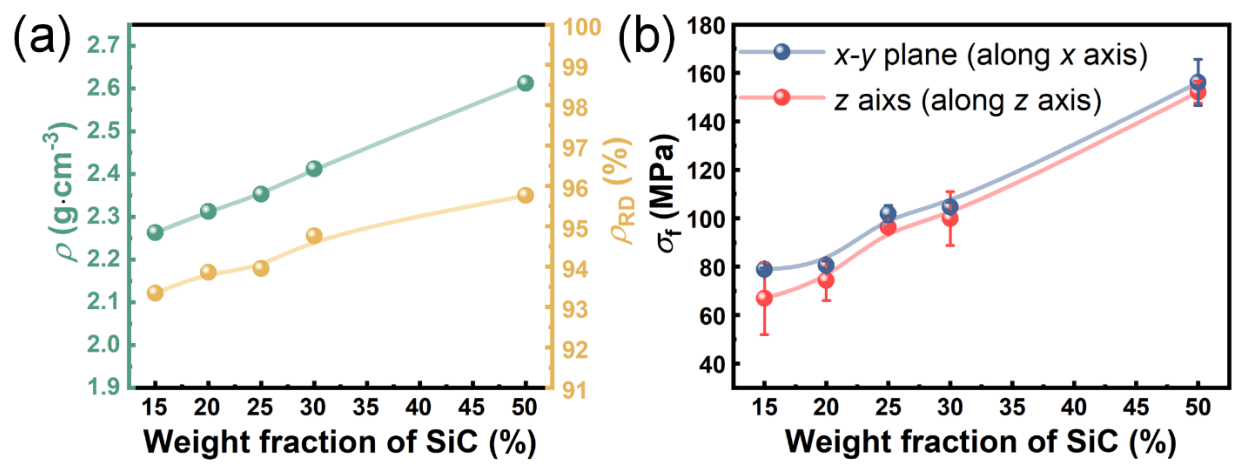

Fig. 6 (a) Densities and relative densities of $\mathrm{SiC} / \mathrm{GF}$ composites with different $\mathrm{SiC}$ concentrations. (b) Flexural strengths of the composites in two principle directions.

is along $z$ axis, and the corresponding flexural strength tested along $x$ axis increases from 79 to $105 \mathrm{MPa}$. When the SiC skeleton becomes completely continuous in $\mathrm{SiC} 50 / \mathrm{GF}$, the flexural strengths with loading directions along $z$ and $x$ axes achieve 152 and $156 \mathrm{MPa}$, respectively, which are about 7.5 times higher than that of the oriented graphite blocks fabricated by hot-pressing of $\mathrm{GFs}$ at $3000{ }^{\circ} \mathrm{C}(21.1 \mathrm{MPa})$ [11]. For the $\mathrm{SiC} / \mathrm{GF}$ composites, the graphite is the weak phase and the $\mathrm{SiC}$ acts as the reinforcement for the flexural strength. With the increase of $\mathrm{SiC}$ concentration, the relative density of the composites also increases (Fig. 6(a)), which means that the porosity of the composites decreases. Hence, the increased $\mathrm{SiC}$ content contributes to the increment of flexural strength of the composites. It also can be seen that the flexural strength in $x-y$ plane is close to $z$ axis direction. The graphite has much lower flexural strength than that of $\mathrm{SiC}$, and thus it can be served as crack in the $\mathrm{SiC}$ /graphite composites and determines the scale of the maximum flaw size $[37,38]$. For the $\mathrm{SiC} / \mathrm{GF}$ composites, when the crack propagates to the weak $\mathrm{SiC} / \mathrm{GF}$ interface or the GF grain, the cracks with similar size to the averaged lateral size of GF are formed by the stress fields at crack tips. Therefore, the flexural strengths of the $\mathrm{SiC} / \mathrm{GF}$ composites in two principle directions are comparable. Furthermore, the flexural strength of composites is also closely connected with their microstructures of fracture surfaces. From the fracture surfaces of the SiC50/GF composite (Figs. $7(a)-7(d)$ ), similar tortuous fracture surfaces can be observed, which contain the intergranular fracture of $\mathrm{SiC}$ and transgranular fracture of GFs, resulting in the similar flexural strengths in two principle directions.

\section{3 Thermal conductivity}

Figure 8(a) shows the TC of the sintered samples in
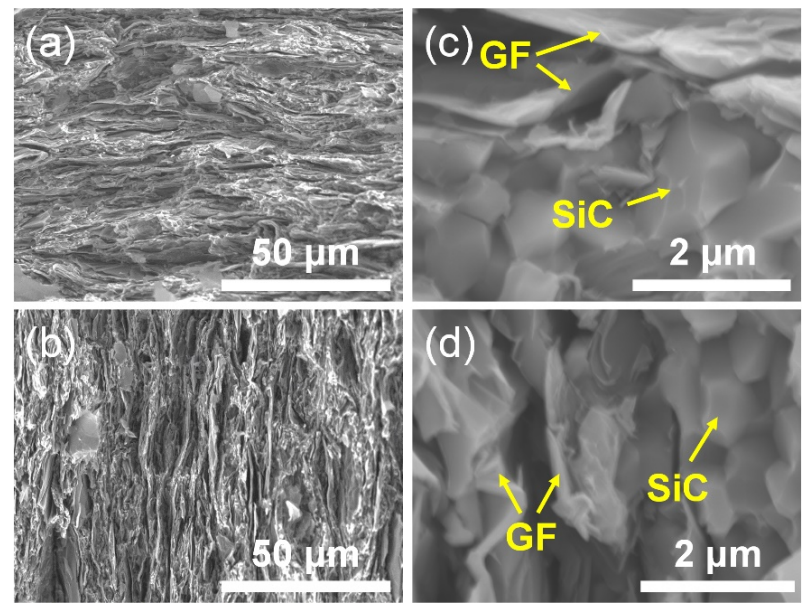

Fig. 7 Fracture surfaces of SiC50/GF composite obtained along (a) $z$ axis and (b) $x$ axis. (c, d) Enlarged images corresponding to (a) and (b), respectively.

two principle directions. The TC in $x-y$ plane is much higher than that in $z$ axis direction, indicating that the composites are highly anisotropic. The TC in $z$ axis direction increases slowly from 18 to $26 \mathrm{~W} \cdot \mathrm{m}^{-1} \cdot \mathrm{K}^{-1}$ with the increase of $\mathrm{SiC}$ concentration, which is ascribed to not only the elevated density of the composites, but also the higher $\mathrm{TC}$ of $\mathrm{SiC}$ skeleton $\left(\sim 60 \mathrm{~W} \cdot \mathrm{m}^{-1} \cdot \mathrm{K}^{-1}\right)$ than that of GF matrix in $z$ axis direction $\left(15 \mathrm{~W} \cdot \mathrm{m}^{-1} \cdot \mathrm{K}^{-1}\right)$ [39]. The TC of $60 \mathrm{~W} \cdot \mathrm{m}^{-1} \cdot \mathrm{K}^{-1}$ for $\mathrm{SiC}$ skeleton was measured by sintering of the $\mathrm{SiC}$ bulk with the same components as the reinforcement. Hence, the heat conduction mainly spreads along the $\mathrm{SiC}$ skeleton (Fig. 8(b)). The TC of the composites in $x-y$ plane first increases from 253 to $289 \mathrm{~W} \cdot \mathrm{m}^{-1} \cdot \mathrm{K}^{-1}$ as the $\mathrm{SiC}$ concentration increases from 15 to $20 \mathrm{wt} \%$, then slightly decreases to $285 \mathrm{~W} \cdot \mathrm{m}^{-1} \cdot \mathrm{K}^{-1}$ when the $\mathrm{SiC}$ concentration reaches $30 \mathrm{wt} \%$, and finally falls to $247 \mathrm{~W} \cdot \mathrm{m}^{-1} \cdot \mathrm{K}^{-1}$ as the $\mathrm{SiC}$ concentration increases to $50 \mathrm{wt} \%$. It was reported that the TC was related with the phonon scattering resulted from pores, defects, and 

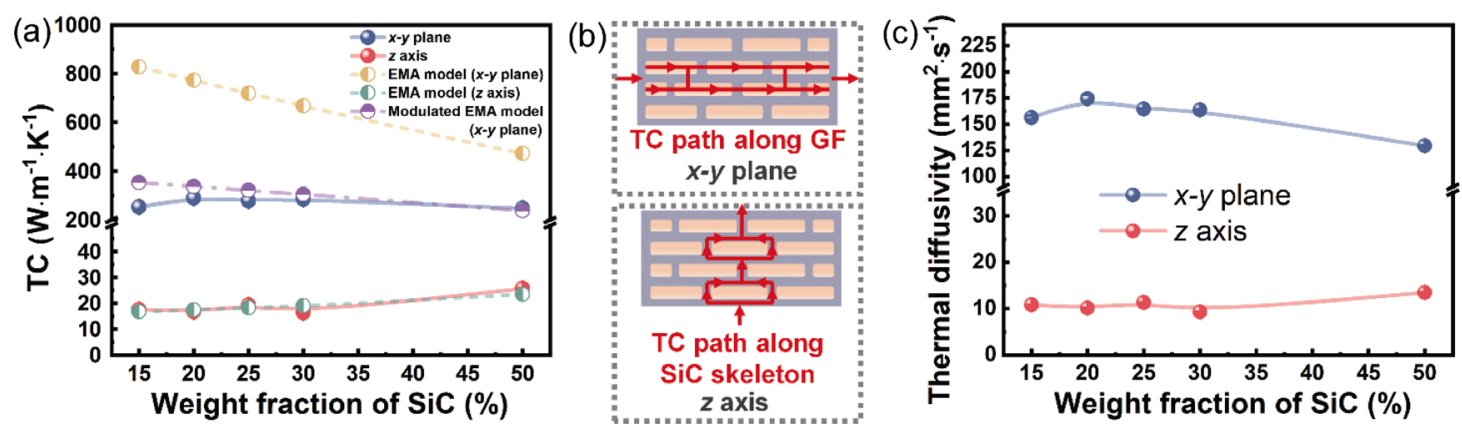

Fig. 8 (a) TC, (b) conductive paths, and (c) thermal diffusivity of the composites in two principal directions.

interfaces in ceramic composites [40,41]. For the anisotropic composites, the orientation degree is also a determining factor for TC [42]. Therefore, the TC should decrease theoretically with the increase of $\mathrm{SiC}$ concentration when defects/interfaces increase and orientation factor $f$ reduces. Nevertheless, the TC first increases as $\mathrm{SiC}$ concentration increases from 15 to 20 $\mathrm{wt} \%$, and remains stable at $285 \mathrm{~W} \cdot \mathrm{m}^{-1} \cdot \mathrm{K}^{-1}$ until $\mathrm{SiC}$ concentration reaches $30 \mathrm{wt} \%$. This phenomenon can be explained by two reasons. Firstly, the SiC particles are sintered to be a continuous reinforcement, which facilitates the densification of $\mathrm{SiC} / \mathrm{GF}$ composites and reduces the phonon scattering resulting from the pores in the composites. Secondly, the GFs with conspicuous directional alignment form a chain structure at high concentrations, which provide the conductive paths (Fig. 8(b)). Hence, GF particles can be considered as continuum in the $\mathrm{SiC} 20 / \mathrm{GF}$ composite, and this structure remains until the $\mathrm{SiC}$ concentration reaches $30 \mathrm{wt} \%$. Further increasing the $\mathrm{SiC}$ concentration to $50 \mathrm{wt} \%$, the integral $\mathrm{SiC}$ skeleton separates the GF grains, which reduces the heat conduction paths in $x-y$ plane of GFs.

Although it is reported that the TC of GF in $x-y$ plane is $1000 \mathrm{~W} \cdot \mathrm{m}^{-1} \cdot \mathrm{K}^{-1}$ [43], the maximum $\mathrm{TC}$ of $\mathrm{SiC} / \mathrm{GF}$ composite only reaches $289 \mathrm{~W} \cdot \mathrm{m}^{-1} \cdot \mathrm{K}^{-1}$, much lower than the theoretical value of GF. To better understand the effect of $\mathrm{SiC}$ reinforcement on the $\mathrm{TC}$ of the $\mathrm{SiC} / \mathrm{GF}$ composites, we used the model developed by Nan et al. [39] within the effective-medium approximation (EMA) to estimate the variation of TC, and then compared with the experimental values. The EMA formulations in two directions are illustrated as Eqs. (4) and (5):

$$
\begin{aligned}
& K_{\mathrm{c}(x y)}= \\
& K_{\mathrm{m}} \frac{2+v\left[\beta_{x y}\left(1-S_{x y}\right)\left(1+<\cos ^{2} \theta \ni\right)+\beta_{z}\left(1-S_{z}\right)\left(1-<\cos ^{2} \theta \succ\right)\right]}{2-v\left[\beta_{x y} S_{x y}\left(1+<\cos ^{2} \theta \ni\right)+\beta_{z} S_{z}\left(1-<\cos ^{2} \theta \succ\right]\right.}
\end{aligned}
$$

$$
\begin{aligned}
& K_{\mathrm{c}(z)}= \\
& K_{\mathrm{m}} \frac{1+v\left[\beta_{x y}\left(1-S_{x y}\right)\left(1-<\cos ^{2} \theta>\right)+\beta_{z}\left(1-S_{z}\right)<\cos ^{2} \theta>\right]}{1-v\left[\beta_{x y} S_{x y}\left(1-<\cos ^{2} \theta>\right)+\beta_{z} S_{z}<\cos ^{2} \theta>\right]}
\end{aligned}
$$

with

$$
\begin{gathered}
\beta_{i}=\frac{K_{i}-K_{\mathrm{m}}}{K_{\mathrm{m}}+S_{i}\left(K_{i}-K_{\mathrm{m}}\right)}(i=x y, z) \\
<\cos ^{2} \theta>=\frac{\int \rho(\theta) \cos ^{2} \theta \sin \theta \mathrm{d} \theta}{\int \rho(\theta) \sin \theta \mathrm{d} \theta}
\end{gathered}
$$

where $K_{\mathrm{c}}, K_{i}$, and $K_{\mathrm{m}}$ are the TC of composites, GF, and $\mathrm{SiC}$, respectively; the subscripts $x y$ and $z$ denote the $x-y$ plane and $z$ axis directions, respectively; $v$ refers to the volume fraction of GF; and $\left\langle\cos ^{2} \theta>\right.$ reflects the statistical orientation of the GFs. $S$ represents the geometrical factor of GF described as $S_{x y}=\pi t / 4 D$ and $S_{z}=1-\pi t / 2 D$, where $t$ and $D$ are the thickness and diameter of the GF, respectively. The $\left\langle\cos ^{2} \theta>\right.$ nearly to 1 is simplified for the general EMA model because almost all the GFs are aligned vertically to the $z$ axis direction. The TCs of GF in $x-y$ plane and $z$ axis directions are taken as 1000 and $15 \mathrm{~W} \cdot \mathrm{m}^{-1} \cdot \mathrm{K}^{-1}$ [43] to calculate the theoretical $\mathrm{TC}$ values of the composites. Meanwhile, the TC of $60 \mathrm{~W} \cdot \mathrm{m}^{-1} \cdot \mathrm{K}^{-1}$ for $\mathrm{SiC}$ is used to carry out the theoretical calculations. It can be seen from Fig. 8(a) that the calculated TC values in $z$ axis direction fit well with the measured values. However, the calculated TCs in $x-y$ plane are obviously higher than those of experiments. The reason is that the introduction of $\mathrm{SiC}$ reinforcement leads to a lot of defects in GFs, including the curve, wrinkle, fold, and fracture of GF grains (Figs. 9(a)-9(d)), which largely intensifies the phonon scattering along $x-y$ plane of GF. From Fig. 9(e), it can be observed many disordered areas of graphite lattice (yellow dashed circle) near the $\mathrm{SiC} / \mathrm{GF}$ interface, which further results in the reduction 

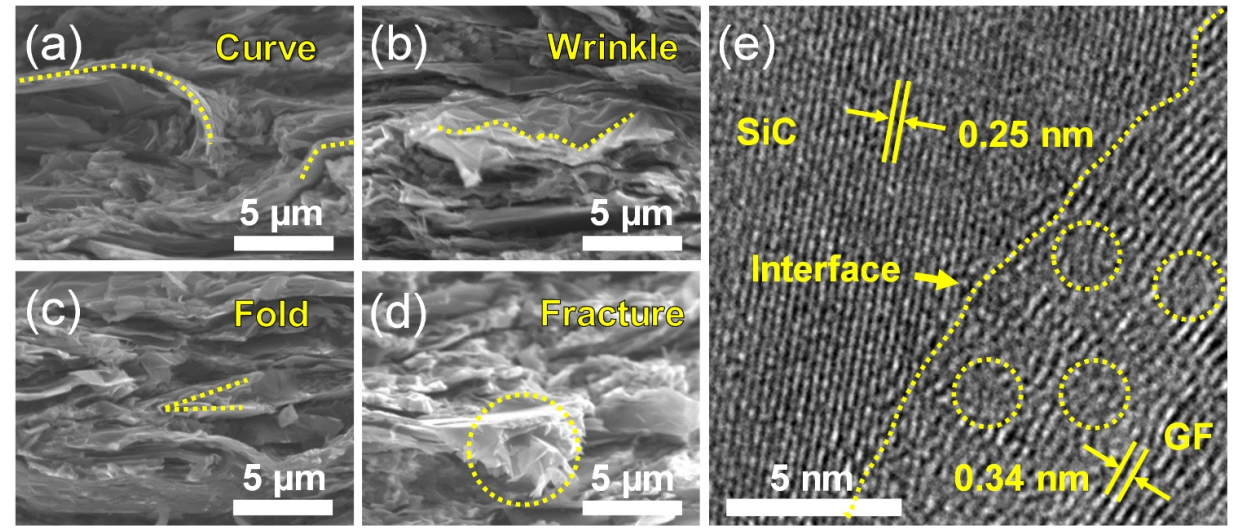

Fig. 9 GF with different defects in SiC/GF composites: (a) curve, (b) wrinkle, (c) fold, and (d) fracture. (e) HRTEM image of $\mathrm{SiC} / \mathrm{GF}$ interface.

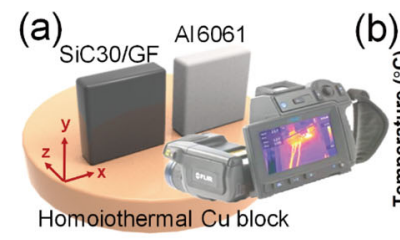

(c)

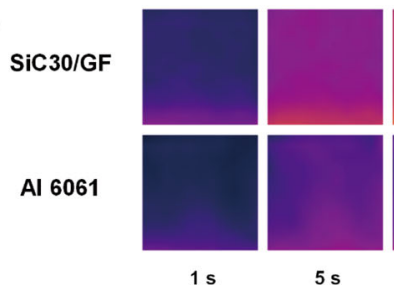

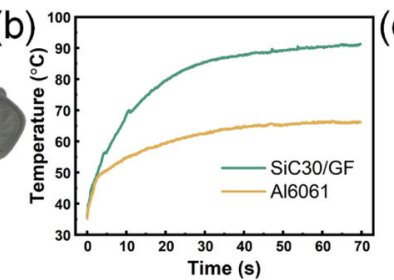

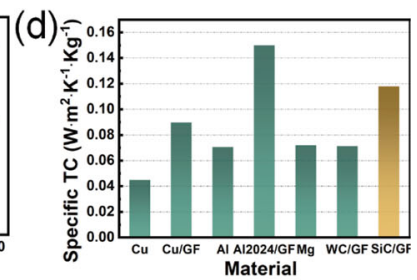

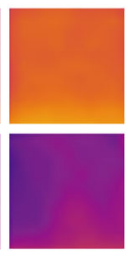

$15 \mathrm{~s}$

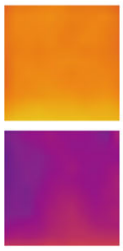

$20 \mathrm{~s}$

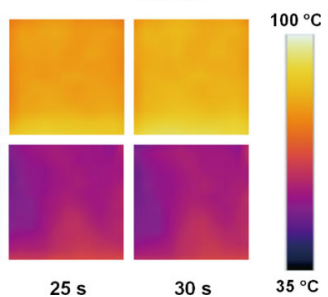

Fig. 10 (a) Schematic diagram of the heat dissipation experiments. (b) Side surface temperature-time curves of the samples. (c) Changes of infrared thermal images over time. (d) Specific TC of SiC30/GF composite compared with several key TMMs $[8,17,21,23]$.

of $\mathrm{TC}$ of the $\mathrm{SiC} / \mathrm{GF}$ composites. Taking the factors above into consideration, the actual TC of GF is much lower than $1000 \mathrm{~W} \cdot \mathrm{m}^{-1} \cdot \mathrm{K}^{-1}$. We used the $\mathrm{TC}$ value of $400 \mathrm{~W} \cdot \mathrm{m}^{-1} \cdot \mathrm{K}^{-1}$ to replace the original $\mathrm{TC}$ of $1000 \mathrm{~W} \cdot \mathrm{m}^{-1} \cdot \mathrm{K}^{-1}$ to modulate the EMA model, and then the experimental TCs of the composites in $x-y$ plane agree well with the modulated EMA model. Thus, the nominal TC of GF would be $400 \mathrm{~W} \cdot \mathrm{m}^{-1} \cdot \mathrm{K}^{-1}$ in $x-y$ plane. Similar tendency is observed between the thermal diffusivity (Fig. 8(c)) and TC of the composites, which indicates that thermal diffusivity is the dominating factor for the heat conductivity compared with heat capacity and density [10].

In order to demonstrate the heat conduction performance of $\mathrm{SiC} / \mathrm{GF}$ composites in $x-y$ plane direction, the commercial Al6061 (TC of $180 \mathrm{~W} \cdot \mathrm{m}^{-1} \cdot \mathrm{K}^{-1}$ ) and $\mathrm{SiC} 30 / \mathrm{GF}$ samples with the same dimension of $10 \mathrm{~mm}$ $\times 10 \mathrm{~mm} \times 2 \mathrm{~mm}$ were placed on a homoiothermal $\mathrm{Cu}$ block $\left(100{ }^{\circ} \mathrm{C}\right)$, and their side surface temperatures were tested by an infrared thermal imager, as shown in Fig. 10(a). The center temperature-time curves of the samples are plotted in Fig. 10(b). It is observed that the $\mathrm{SiC} 30 / \mathrm{GF}$ composite displays a higher raising rate than A16061. As time goes on, the surface temperatures of the $\mathrm{SiC} 30 / \mathrm{GF}$ composite and Al6061 sample finally reach 90 and $65{ }^{\circ} \mathrm{C}$, respectively, which should be ascribed to the higher TC of the $\mathrm{SiC} 30 / \mathrm{GF}$ composite compared with A16061. This can be further verified by the infrared thermal images (Fig. 10(c)), where the $\mathrm{SiC} 30 / \mathrm{GF}$ composite with higher TC shows more shallow color (at higher temperatures) over time.

The specific TC is also a significant parameter to evaluate the performance of advanced TMMs. It can be seen from Fig. 10(d) that the specific TC $(0.118$ $\left.\mathrm{W} \cdot \mathrm{m}^{2} \cdot \mathrm{K}^{-1} \cdot \mathrm{kg}^{-1}\right)$ of $\mathrm{SiC} 30 / \mathrm{GF}$ composite is 2.5 times higher than that of $\mathrm{Cu}\left(0.045 \mathrm{~W} \cdot \mathrm{m}^{2} \cdot \mathrm{K}^{-1} \cdot \mathrm{kg}^{-1}\right)$ [17] and nearly 1.5 times as high as that of $\mathrm{Al}(0.088$ $\mathrm{W} \cdot \mathrm{m}^{2} \cdot \mathrm{K}^{-1} \cdot \mathrm{kg}^{-1}$ ) [21]. The relative low $\mathrm{TC}$ of $\mathrm{SiC} / \mathrm{GF}$ 
composite is greatly compensated by the low density compared with $\mathrm{Cu} / \mathrm{GF}$ composite [17]. Only Al2024/GF composite can be comparable to our study [8], but its poor tensile strength $(22 \mathrm{MPa})$ limits the further application in advanced TMMs. Compared with metal/ alloy reinforced highly oriented GF composites, it is more complex and expensive to prepare the $\mathrm{SiC} / \mathrm{GF}$ composites. However, the high flexural strength and specific $\mathrm{TC}$ of $\mathrm{SiC} / \mathrm{GF}$ composites can not only ensure the serviceability, but also remove heat effectively, which could be applied in the field of aerospace and other extreme conditions in the future.

\section{4 Thermal expansion}

The measured and calculated CTE values of the composites in two principle directions are displayed in Fig. 11. Obvious discrepancy of CTE in $x-y$ plane and $z$ axis directions indicates good anisotropy of $\mathrm{SiC} / \mathrm{GF}$ composites. The CTE in $x-y$ plane increases slightly from $1.17 \times 10^{-6}$ to $2.91 \times 10^{-6} \mathrm{~K}^{-1}$ with the $\mathrm{SiC}$ concentration increasing from 15 to $50 \mathrm{wt} \%$ (Fig. 11(a)). The CTE in $z$ axis drops significantly from $14.8 \times$ $10^{-6} \mathrm{~K}^{-1}$ for $\mathrm{SiC} 15 / \mathrm{GF}$ to $5.32 \times 10^{-6} \mathrm{~K}^{-1}$ for $\mathrm{SiC} 50 / \mathrm{GF}$ (Fig. 11(b)). The measured CTE values in $z$ axis are much lower than those of the highly oriented graphite blocks, demonstrating that the $\mathrm{SiC}$ skeleton constrains the thermal expansion of the graphite matrix effectively.

To understand the effect of $\mathrm{SiC}$ concentration on the thermal expansion behavior of $\mathrm{SiC} / \mathrm{GF}$ composites, Turner model was used to estimate the theoretical CTE values [44]. The weight fraction is converted to volume fraction for the CTE calculation. Turner model assumes only uniform hydrostatic stresses which exist in the phases of the composite. The thermal expansion of each phase changes at the same rate with the composites should be well described by the Turner model $[45,46]$.
Because the CTE of $\mathrm{SiC}\left(4.7 \times 10^{-6} \mathrm{~K}^{-1}\right)$ is close with that of graphite in basal plane $\left(-1.5 \times 10^{-6} \mathrm{~K}^{-1}\right)$, the internal stress of composites in this direction is low. Therefore, the experimental CTE of composites in $x-y$ plane direction is consistent with the values calculated by Turner model.

From Fig. 11(b), it is noted that the measured CTE in $z$ axis of the composites is lower than that of the predicted CTE by Turner model, which demonstrates that there exists a thermal stress between $\mathrm{SiC}$ and $\mathrm{GF}$ in $z$ axis direction. The thermal stress is introduced by the large difference in thermal expansion between $\mathrm{SiC}$ and $\mathrm{GF}$ in $z$ axis direction. When the $\mathrm{SiC}$ concentration reaches $20 \mathrm{wt} \%$, the incompact $\mathrm{SiC}$ skeleton is formed in the composite and the GF grains cannot be separated by the skeleton completely. Therefore, the thermal expansion of GF in $z$ axis direction cannot be constrained by the $\mathrm{SiC}$ skeleton effectively in the $\mathrm{SiC} 20 / \mathrm{GF}$ composite. This structure is remained until the $\mathrm{SiC}$ weight fraction increases to $30 \%$. Thus, the CTE values of $\mathrm{SiC} / \mathrm{GF}$ composites are higher than those of $\mathrm{SiC}$ but much lower than those of GF in $z$ axis direction with the $\mathrm{SiC}$ concentration in the range of 20-30 wt $\%$. According to the elastic theory, thermal expansion and stress can be connected. Hence, we can calculate the CTE in $z$ axis of GF to be $20.3 \times 10^{-6} \mathrm{~K}^{-1}$ (see the detailed calculation process in Section $\mathrm{S} 7$ in the ESM) and replace the theoretical CTE $\left(28 \times 10^{-6} \mathrm{~K}^{-1}\right)$ of GF to modulate Turner models. As can be seen from Fig. 11(b), the measured data agrees with the modulated Turner model when the $\mathrm{SiC}$ concentration changes in the range of $20-30 \mathrm{wt} \%$. Meantime, the lower relative density indicates more residual pores in the composites, which facilitates the absorption of thermal stress. When the $\mathrm{SiC}$ concentration reaches $50 \mathrm{wt} \%$, the $\mathrm{SiC}$ forms an integral continuous skeleton, which plays a
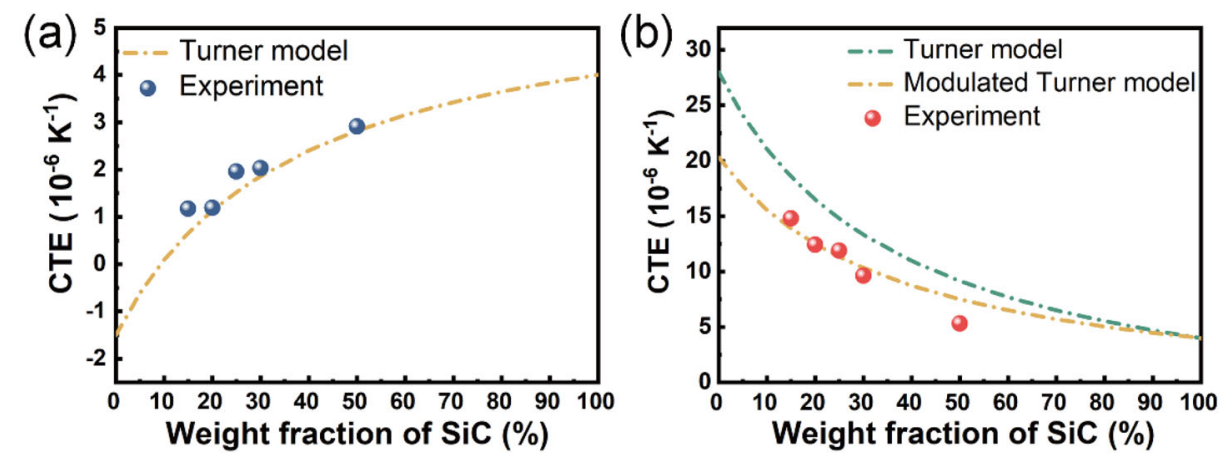

Fig. 11 Measured and calculated CTE values of the composites in (a) $x-y$ plane and (b) $z$ axis directions. The curves are the modeling predictions. 
rigid constraint for the GF expansion. Thus, the CTE of composites is close to that of $\mathrm{SiC}$.

\section{Conclusions}

Continuous SiC skeleton reinforced highly oriented GF composites with excellent flexural strength and high specific TC were successfully fabricated via vacuum filtration and SPS route. The densification and flexural strength of the $\mathrm{SiC} / \mathrm{GF}$ composites increased with the increase of $\mathrm{SiC}$ concentration. The $\mathrm{SiC} / \mathrm{GF}$ composites possessed high orientation with Lotgering factor higher than $88 \%$ when the $\mathrm{SiC}$ concentration was $\leqslant 30 \mathrm{wt} \%$, which endowed the composites with obviously anisotropic properties. Oriented GFs with chain conductive structure in the $\mathrm{SiC} / \mathrm{GF}$ composites promoted the formation of effective thermal conductive networks, which ensured the high TC of the composites. With the $\mathrm{SiC}$ concentration $\geqslant 20 \mathrm{wt} \%$, the $\mathrm{SiC}$ skeleton became continuous in the composites. The continuous $\mathrm{SiC}$ skeleton not only improved the flexural strength but also restrained the CTE in $z$ axis effectively by introducing the thermal stress. Compared with most of the existent TMMs, the $\mathrm{SiC} 30 / \mathrm{GF}$ composites exhibited the optimal comprehensive properties with the flexural strength of $105 \mathrm{MPa}$ and specific TC of $0.118 \mathrm{~W} \cdot \mathrm{m}^{2} \cdot \mathrm{K}^{-1} \cdot \mathrm{kg}^{-1}$.

\section{Acknowledgements}

This work was supported by the National Natural Science Foundation of China (Nos. 51872222 and 92163112), the National Key R\&D Program of China (No. 2017YFB0310400), the Shaanxi Innovation Capacity Support Program (No. 2018TD-031), and the Research on Multi-Chip Parallel Current Sharing Technology of Power Electronic Devices Based on Electric-Thermal Optimization (No. SGAH0000KJJS1900437).

\section{Electronic Supplementary Material}

Supplementary material is available in the online version of this article at https://doi.org/10.1007/s40145-021-0542-6.

\section{References}

[1] Song H, Liu J, Liu B, et al. Two-dimensional materials for thermal management applications. Joule 2018, 2: 442-463.

[2] Wei Z, Xie W, Zhang X, et al. Preparation of AlN micro- honeycombs with high permeability via freeze-casting. $J$ Eur Ceram Soc 2020, 40: 4462-4468.

[3] Wei Z, Xie W, Ge B, et al. Enhanced thermal conductivity of epoxy composites by constructing aluminum nitride honeycomb reinforcements. Compos Sci Technol 2020, 199: 108304.

[4] Huang Y, Su Y, Li S, et al. Fabrication of graphite film/ aluminum composites by vacuum hot pressing: Process optimization and thermal conductivity. Compos B: Eng 2016, 107: 43-50.

[5] Zhang K, Xia HY, Wang B, et al. Preparation and thermalphysical properties of three dimensional bicontinuous $\mathrm{SiC} / \mathrm{Cu}-\mathrm{Si}$ composite. Mater Sci Forum 2014, 804: 187-190.

[6] Huang Y, Hu J, Yao Y, et al. Manipulating orientation of silicon carbide nanowire in polymer composites to achieve high thermal conductivity. Adv Mater Interfaces 2017, 4: 1700446.

[7] Li J, Zhang H, Wang L, et al. Optimized thermal properties in diamond particles reinforced copper-titanium matrix composites produced by gas pressure infiltration. Compos A: Appl Sci Manuf 2016, 91: 189-194.

[8] Oddone V, Boerner B, Reich S. Composites of aluminum alloy and magnesium alloy with graphite showing low thermal expansion and high specific thermal conductivity. Sci Technol Adv Mater 2017, 18: 180-186.

[9] Fang X, Jiang L, Pan L, et al. High-thermally conductive AlN-based microwave attenuating composite ceramics with spherical graphite as attenuating agent. $J A d v$ Ceram 2021, 10: 301-319.

[10] Yuan G, Li X, Dong Z, et al. Graphite blocks with preferred orientation and high thermal conductivity. Carbon 2012, 50: 175-182.

[11] Liu Z, Guo Q, Shi J, et al. Graphite blocks with high thermal conductivity derived from natural graphite flake. Carbon 2008, 46: 414-421.

[12] Deng Y, Zhang Y, Zhang N, et al. Preparation and characterization of pure $\mathrm{SiC}$ ceramics by high temperature physical vapor transport induced by seeding with nano $\mathrm{SiC}$ particles. J Mater Sci Technol 2019, 35: 2756-2760.

[13] Wei Z, Li K, Ge B, et al. Synthesis of nearly spherical AlN particles by an in situ nitriding combustion route. $J A d v$ Ceram 2021, 10: 291-300.

[14] Boden A, Boerner B, Kusch P, et al. Nanoplatelet size to control the alignment and thermal conductivity in coppergraphite composites. Nano Lett 2014, 14: 3640-3644.

[15] Saxena A, Singh N, Kumar D, et al. Effect of ceramic reinforcement on the properties of metal matrix nanocomposites. Mater Today: Proc 2017, 4: 5561-5570.

[16] Ren S, Chen J, He X, et al. Effect of matrix-alloyingelement chromium on the microstructure and properties of graphite flakes/copper composites fabricated by hot pressing sintering. Carbon 2018, 127: 412-423.

[17] Firkowska I, Boden A, Boerner B, et al. The origin of high thermal conductivity and ultralow thermal expansion in copper-graphite composites. Nano Lett 2015, 15: 4745 4751.

[18] Roudini G, Tavangar R, Weber L, et al. Influence of reinforcement contiguity on the thermal expansion of 
alumina particle reinforced aluminium composites. Int $J$ Mater Res 2010, 101: 1113-1120.

[19] Zhao LZ, Zhao MJ, Cao XM, et al. Thermal expansion of a novel hybrid $\mathrm{SiC}$ foam-SiC particles-Al composites. Compos Sci Technol 2007, 67: 3404-3408.

[20] Chen W, Miyamoto Y, Matsumoto T, et al. Preparation of AlN ceramic bonded carbon by gelcasting and spark plasma sintering. Carbon 2010, 48: 3399-3404.

[21] Zhang Z, Ge B, Xie W, et al. Effect of Si alloying content on the microstructure and thermophysical properties of $\mathrm{SiC}$ honeycomb/Al-Mg-Si composites prepared by spontaneous infiltration. Ceram Int 2020, 46: 10934-10941.

[22] Xue C, Bai H, Tao PF, et al. Thermal conductivity and mechanical properties of flake graphite/Al composite with a SiC nano-layer on graphite surface. Mater Des 2016, 108: $250-258$.

[23] Zhang X, Xie W, Ge B, et al. Enhancing the mechanical and thermophysical properties of highly oriented graphite flake composites by formation of a uniform three dimensional tungsten carbide skeleton reinforcement. Compos A: Appl Sci Manuf 2020, 131: 105800.

[24] Zhang X, Shi Z, Zhang X, et al. Three dimensional AlN skeleton-reinforced highly oriented graphite flake composites with excellent mechanical and thermophysical properties. Carbon 2018, 131: 94-101.

[25] Liu J, Zhou X, Tatarko P, et al. Fabrication, microstructure, and properties of $\mathrm{SiC} / \mathrm{Al}_{4} \mathrm{SiC}_{4}$ multiphase ceramics via an in-situ formed liquid phase sintering. J Adv Ceram 2020, 9: 193-203.

[26] Zhang Z, Shi Z, Yang B, et al. Preparation and anisotropic thermophysical properties of $\mathrm{SiC}$ honeycomb/Al-Mg-Si composite via spontaneous infiltration. Prog Nat Sci: Mater Int 2019, 29: 177-183.

[27] Luo X, Yang Y, Liu C, et al. The thermal expansion behavior of unidirectional $\mathrm{SiC}$ fiber-reinforced $\mathrm{Cu}$-matrix composites. Scripta Mater 2008, 58: 401-404.

[28] Huang Y, Wan C. Controllable fabrication and multifunctional applications of graphene/ceramic composites. $J$ Adv Ceram 2020, 9: 271-291.

[29] Zhang Y, Han H, Wang N, et al. Improved heat spreading performance of functionalized graphene in microelectronic device application. Adv Funct Mater 2015, 25: 4430-4435.

[30] Wan J, Duan RG, Mukherjee AK. Spark plasma sintering of silicon nitride/silicon carbide nanocomposites with reduced additive amounts. Scripta Mater 2005, 53: 663-667.

[31] Qin Y, Liu JX, Li F, et al. A high entropy silicide by reactive spark plasma sintering. J Adv Ceram 2019, 8: 148-152.

[32] Baskut S, Cinar A, Turan S. Directional properties and microstructures of spark plasma sintered aluminum nitride containing graphene platelets. J Eur Ceram Soc 2017, 37: 3759-3772.

[33] Lotgering FK. Topotactical reactions with ferrimagnetic oxides having hexagonal crystal structures-I. J Inorg Nucl Chem 1959, 9: 113-123.

[34] Huang $\mathrm{R}$, Gu $\mathrm{H}$, Zhang J, et al. Effect of $\mathrm{Y}_{2} \mathrm{O}_{3}-\mathrm{Al}_{2} \mathrm{O}_{3}$ ratio on inter-granular phases and films in tape-casting $\alpha$-SiC with high toughness. Acta Mater 2005, 53: 2521-2529.
[35] Rutkowski PJ, Kata D. Thermal properties of AlN polycrystals obtained by pulse plasma sintering method. $J$ Adv Ceram 2013, 2: 180-184.

[36] Xia H, Zhang X, Shi Z, et al. Mechanical and thermal properties of reduced graphene oxide reinforced aluminum nitride ceramic composites. Mater Sci Eng: A 2015, 639: 29-36.

[37] Ramirez C, Miranzo P, Belmonte M, et al. Extraordinary toughening enhancement and flexural strength in $\mathrm{Si}_{3} \mathrm{~N}_{4}$ composites using graphene sheets. J Eur Ceram Soc 2014, 34: $161-169$.

[38] Sedlák R, KovalLíková A, Girman V, et al. Fracture characteristics of $\mathrm{SiC} /$ graphene platelet composites. $J$ Eur Ceram Soc 2017, 37: 4307-4314.

[39] Nan C, Birringer R, Clarke DR, et al. Effective thermal conductivity of particulate composites with interfacial thermal resistance. J Appl Phys 1997, 81: 6692-6699.

[40] Ge B, Shi Z, Zhou C, et al. Enhanced thermoelectric performance of $\mathrm{N}$-type eco-friendly material $\mathrm{Cu}_{1-x} \mathrm{Ag}_{x} \mathrm{FeS}_{2}$ $(x=0-0.14)$ via bandgap tuning. J Alloys Compd 2019, 809: 151717.

[41] Zhou C, Lee YK, Cha J, et al. Defect engineering for high-performance n-type PbSe thermoelectrics. J Am Chem Soc 2018, 140: 9282-9290.

[42] Zhou S, Chiang S, Xu J, et al. Modeling the in-plane thermal conductivity of a graphite/polymer composite sheet with a very high content of natural flake graphite. Carbon 2012, 50: 5052-5061.

[43] Ueno T, Yoshioka T, Ogawa J, et al. Highly thermal conductive metal/carbon composites by pulsed electric current sintering. Synth Met 2009, 159: 2170-2172.

[44] Turner PS. Thermal-expansion stresses in reinforced plastics. J Res Natl Bureau Stand 1946, 37: 239.

[45] Nam TH, Requena G, Degischer P. Thermal expansion behaviour of aluminum matrix composites with densely packed SiC particles. Compos A: Appl Sci Manuf 2008, 39: $856-865$.

[46] Guo Y, Guo H, Gao B, et al. Rapid consolidation of ultrafine grained W-30 wt.\% $\mathrm{Cu}$ composites by field assisted sintering from the sol-gel prepared nanopowders. J Alloys Compd 2017, 724: 155-162.

Open Access This article is licensed under a Creative Commons Attribution 4.0 International License, which permits use, sharing, adaptation, distribution, and reproduction in any medium or format, as long as you give appropriate credit to the original author(s) and the source, provide a link to the Creative Commons licence, and indicate if changes were made.

The images or other third party material in this article are included in the article's Creative Commons licence, unless indicated otherwise in a credit line to the material. If material is not included in the article's Creative Commons licence and your intended use is not permitted by statutory regulation or exceeds the permitted use, you will need to obtain permission directly from the copyright holder.

To view a copy of this licence, visit http://creativecommons. org/licenses/by/4.0/. 